\title{
The Role of Decadal Kelvin Wave in the Western of Sumatra and Along the South Coast of Java using Frequency-Wavenumber 2D Spectral Analysis
}

\author{
Hanah Khoirunnisa ${ }^{1, *}$, Reno Arief Rachman ${ }^{1}$, Nining Sari Ningsih ${ }^{2}$, Fadli Syamsudin ${ }^{1}$ \\ ${ }^{1}$ Agency for the Assessment and Application of Technology (BPPT), Jakarta, Indonesia \\ ${ }^{2}$ Bandung Institute of Technology, Bandung, Indonesia
}

* Corresponding author : hanah.khoirunnisa@bppt.go.id

Tel.: +62 85760378214; fax: +62 85742319887

Received: Oct 2, 2019; Accepted: Feb 24, 2020

DOI: 10.25299/jgeet.2020.5.1.3889

\begin{abstract}
This study observed the decadal variability of the sea surface height anomaly (SSHA) and identified the decadal Kelvin wave propagation along west-Sumatra and south coast of Java. SSHA data and the vertical distribution of sea temperature for 64 years based on Hybrid Coordinate Ocean Model (HYCOM) model resulted has already used in this research. There are several methods to identify the propagation of decadal Kelvin wave. These methods were low-pass filter by cut-off 1 and 8 years, visual analytic by using Hovmöller diagram method, and frequency-wavenumber 2D spectral analysis to identify the Kelvin wave propagation and its period. The decadal Kelvin wave could be observed in west coast of Sumatra and along south coast of Java. There are three propagations of decadal Kelvin wave and their velocities were 1.029x10-3 m/s (1974 - 1976), 0.21 $\mathrm{m} / \mathrm{s}$ during $1985-1986$ ), and 6.86x10-4 m/s for 1998 to 2001 trough west Sumatra and southern Java. The frequency-wavenumber 2D spectral analysis produced the improvement of Kelvin wave and it has the period of 7.25 years. The occurrence of the Kelvin wave has a relation to IOD index. The average of the IOD index when the decadal Kelvin wave was occurring must be the negative value, its value was a -0.21 .
\end{abstract}

Keywords: Decadal Variability, Sea Surface Height Anomaly, Kelvin Wave, Frequency-Wavenumber 2D Spectral Analysis

\section{Introduction}

There were several forms of variability in the Indian Ocean. They should be named as intra-seasonal, seasonal, inter-annual, decadal, and inter-decadal. The inter-annual variability of sea level change has been observed in the western Indian Ocean and also it was influenced by climate phenomenon (Mahongo et al., 2014). The Pacific Decadal Oscillation (PDO) was an example of the decadal variability has ever been observed. PDO is described as a form of El Nino on climate variability in the Pacific Ocean. They have two-phases, it should be named as the cold and warm phase. It has a spatial and temporal scale. Technically, the observation of PDO has been done in the last of the 20th century (Mantua and Hare, 2002). Decadal variation is strongly influenced by the meteorology condition (Mahongo, et al 2014). Nowadays, there were three scales the seaatmosphere interaction has been known, it was named as: interannual (3 to 7 years), decadal (10 to 11 years), and inter-decadal (16 to 18 years) (Mann and Park, 1996; Park et al, 2000).

Correspondingly, the Indian Ocean has also the decadal variability. There were inter-annual and inter-decadal variability on the ocean-atmosphere interactions in a large basin of the Indian Ocean. It was determined by the monthly of SST and surface wind (Qian et al., 2001). The interannual variability Indian Ocean Dipole (IOD) has also the period of decadal. The decadal modulation of the IOD has influenced the global climate (Yuan et al., 2008). Additionally, sea level anomalies along south coast of Java have the decadal period (Khoirunnisa, 2015). There is a correlation between thermocline depth variation and IOD index (Ashok et al., 2004; Schott et al., 2009). The IOD index was a range of the both pressures, between western of Sumatra and the eastern of Africa. It can be influenced the sea surface height anomaly around the India Ocean (Saji et al, 1999; Susanto et al, 2001; Khoirunnisa, 2015). The SST anomalies occur near the south coast of Java and western Sumatra and declining in the long term around \pm $3^{\circ} \mathrm{C}$ (Saji et al, 1999; Yuan et al, 2008; Sambodho et al, 2017; and Wisha and Khoirunnisa, 2017).

Similar with the IOD, the sea surface height (SSH) in the Indian Ocean has also the decadal variability. It was observed in the year of 1992 to 2001, as well as in the period of 2001 to 2008 (Church et al., 2004 in Han et al., 2008). In addition to SSH data, the North Indian Ocean and the South Indian Ocean have been first observed the decadal variability of the SSTA over the period of 1961 - 2000 (Han et al., 2008). Tropical Indian Ocean region has an important role on climate. Han et al. (2008) points out that there was a decadal variability of the thermocline depth and the heat content in the tropical Indian Ocean during 1992 to 2008.In the Indian Ocean have observed a link between atmospheric circulation and monsoon or the precipitation anomalies (Qian et al., 2001).

This study aims to assess the existence of the decadal Kelvin wave and their influence on the thermocline in the West Coast of Sumatra and Southern Java. The used methods were the visual analysis with Hovmöller diagram and frequencywavenumber 2D spectral analysis to prove the existence of the Kelvin wave.

\section{Data and Methods}

The data will be used is the SSHA and temperature per depth along the western coast of Sumatra and southern Java (Figure 1). These were a result of three-dimension hydrodynamic model called the Hybrid Coordinate Ocean 
Model (HyCOM) for 64 years with a range of years from 1950 to 2013 conducted by Ningsih et al. (2012). In addition, we also used the monthly Indian Ocean Dipole (IOD) index at the year of 1958 to 2010.

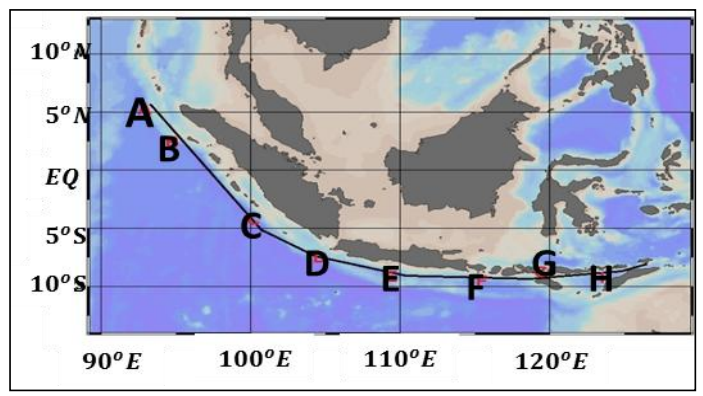

Fig.1.The research area along the western of Sumatra and southern of Java and Lesser Islands was marked up by $\mathrm{A}-\mathrm{H}$ point.

There are several methods to determine the decadal variability of the SSHA and Kelvin wave. They were the lowpass filter, Hovmöller diagram, and 2D frequency-wavenumber spectral analysis (dispersive diagram). The low-pass filter was applied by a year cut-off to remove the seasonal variability. As well as 6 and 8 years cut-off was applied to catch the decadal period of the SSHA. The next method was the frequencywavenumber 2D spectral analysis (diagram dispersive) to identify the existence of Kelvin wave propagation.

\subsection{Frequency-Wavenumber 2D Spectral Analysis}

Frequency-wavenumber 2D spectral analysis was used to identify the presence of Kelvin wave propagation in the southern of Java. It was described with a curve that was often called the dispersion curve.

The Kelvin wave was identified by the line of the theoretical Kelvin wave. The lines can be obtained by the linear phase velocity of the Kelvin wave. The dispersion relation of the wave equation can be stated as an Equation 1:

$$
\omega^{2}=g k \tanh (k H)
$$

For the shallow water, $k H \rightarrow 0$, $\operatorname{sotanh}(k H)=k H$, then Equation 2 become:

$$
\omega=k \sqrt{g H}
$$

In addition, the phase speed equation of the Kelvin wave can be written:

$$
c=\omega / k
$$

Where:

$\omega \quad:$ The angular frequency

$k \quad:$ Wavenumber

The Equation 3 can be written again become:

$$
\begin{aligned}
c & =\sqrt{g h} \\
\frac{\omega}{k} & =\sqrt{g h} \\
\tan & \propto=\sqrt{g h}
\end{aligned}
$$

\begin{tabular}{|c|c|c|}
\hline Parameter & Value & Description \\
\hline$h$ & $0.4 \mathrm{~km}$ & thickness of fluid layer (m) \\
\hline$g^{\prime}$ & $\begin{array}{c}4.89 \times 10 \\
{ }^{3} \mathrm{~km} / \mathrm{s}^{2}\end{array}$ & reduced gravity $\left(\mathrm{m} / \mathrm{s}^{2}\right)$ \\
\hline$f^{\prime}$ & $\begin{array}{r}2.28 \times 10 \\
{ }^{5} \text { second }\end{array}$ & $\begin{array}{l}\text { The Coriolis parameter }(\mathrm{rad} / \mathrm{s}) \text { at } \\
\text { the } 9^{\circ} \mathrm{S}\end{array}$ \\
\hline$R$ & $\begin{array}{c}1939.7 \\
\mathrm{~km}\end{array}$ & Deformation of Rossby radius (m) \\
\hline
\end{tabular}

Where:

$$
\begin{array}{ll}
\propto & : \text { The angle between } \omega \text { and } k \\
g & : \text { The gravitational acceleration }\left(\mathrm{m} / \mathrm{s}^{2}\right) \\
h & : \text { The average of depth }(\mathrm{m}) \\
c & : \text { The phase velocity }(\mathrm{m} / \mathrm{s})
\end{array}
$$

Table 1. The parameters that be used in the frequency-wavenumber 2D spectral analysis.
The value of thickness of fluid layer and reduced gravity had been got from National Program of the Indonesian Government (NP), Joint Indonesia German Indian Ocean Expedition (JGIE), and Volunteer Observing Ship - Japanese Global Ocean Observing System (VOS-JGOOS).

Based on Roisin and Jean (2008), the thickness of fluid layer was a thickness of uniform density of fluid layer. Its Equation can be written by:

$$
h=-\Delta \rho \frac{\partial z}{\partial \rho}
$$

Where:

$\Delta \rho$

$\frac{\partial z}{\partial \rho} \quad$ :The change of the depth into density $\left(\mathrm{m}^{4} / \mathrm{kg}\right)$

The Reduced gravity was the acceleration in the depth which has the different between its gravitational acceleration and the surface gravitational acceleration. The reduce gravity has an equation as bellows:

$$
g^{\prime}=g \Delta \rho / \rho_{0}
$$

Where:

$\begin{array}{ll}\Delta \rho & : \text { The density gradient }\left(\mathrm{kg} / \mathrm{m}^{3}\right) \\ \mathrm{g} & : \text { The gravitational acceleration }\left(\mathrm{m} / \mathrm{s}^{2}\right) \\ \mathrm{g}^{\prime} & : \text { The reduced gravity }\left(\mathrm{m} / \mathrm{s}^{2}\right) \\ \rho_{0} & : \text { The reference of density }\left(\mathrm{kg} / \mathrm{m}^{3}\right)\end{array}$

\section{Results and Discussion}

\subsection{Hovmöller Diagram}

Figures 2 and 3 have shown the SSHA variation along the west coast of Sumatra and south coast of Java during 1950 to 2013 (64 years). The right side of the Figure 2shows the variation of the SSHA by low-pass filter 8 years cut-off. It presents the eastward propagation of the decadal variability of the SSHA with the range of 11 and 14 years. The eastward propagations were illustrated in Figure 3. The eastward propagation is indicated as a decadal Kelvin waves. Furthermore, to make itto be sure, the last method was applied and it was called by the frequency-wavenumber 2D spectral analysis (dispersive diagram).

There are three times of the eastward propagations along western Sumatra and southern Java. They had occurred at the year of 1974 to 1976,1985 to 1986 , and 1998 until 2001. These phase speed were $1.029 \times 10-3 \mathrm{~m} / \mathrm{s} ; 0.21 \mathrm{~m} / \mathrm{s}$; and $6.86 \times 10-4 \mathrm{~m} / \mathrm{s}$ (Figure 3).

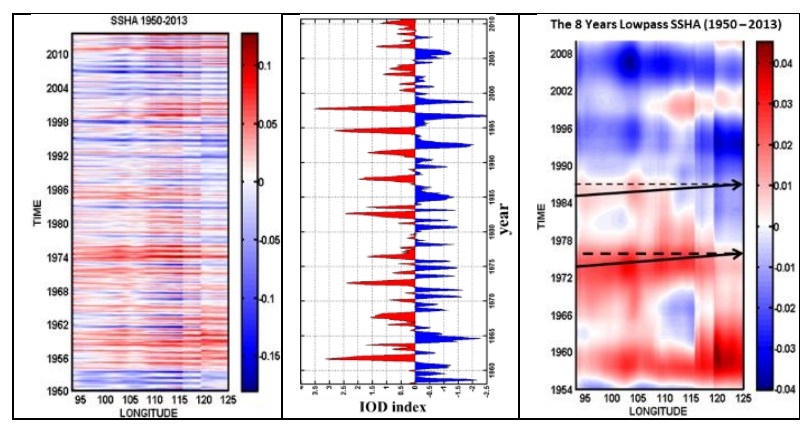

Fig 2 . The sea level anomaly visualization has been applied by Hovmöller diagram. The raw data (up) and the low-pass filter data by 8 years cut-off (bottom right-side) and the IOD index (bottom leftside).

There was the relation between the occurrence of the Kelvin wave and the IOD index. Table 2 shows that the decadal Kelvin was occurred as well as the negative IOD. The average of IOD index when the decadal Kelvin wave was occurring is a -0.21 . 
Table 2. The relation between the Indian Ocean Dipole (IOD) index and the occurrence of the decadal Kelvin wave

\begin{tabular}{cc}
\hline The IOD index & $\begin{array}{c}\text { The occurrence of decadal Kelvin } \\
\text { wave }\end{array}$ \\
\hline 0.035 & $1974-1976$ \\
-0.5 & $1985-1986$ \\
-0.19 & $1998-2001$ \\
\hline
\end{tabular}

\subsection{Frequency-Wavenumber 2D Spectral Analysis Results}

There was an assumptionof the decadal Kelvin wave existence as well as in Figures 4 and 5. Nevertheless, it should be proven by some methods. It was a frequency - wavenumber 2D spectral analysis. When the black linear lineis wedged by the energy spectrum, it shows the Kelvin wave propagation. Figure 4 is the result of dispersive diagram for non-filter data. It was reflecting the Kelvin wave propagation. As well as Figure 5 is the result of dispersive diagram for the low-pass filter data by 3 years cut-off. Both of pictures stated that there was the existence of the decadal Kelvin wave.

Kelvin waves which were detected by the method of frequency-wavenumber 2D spectral analysis (Figures 4 and 5) have the variety period, which was 19.25 years (inter-decadal), 11 years (decadal), and 6.55 years (inter-annual). So, the eastward propagation in Figure 2,could be indicated as a decadal Kelvin wave propagation which has a period of 11 years.

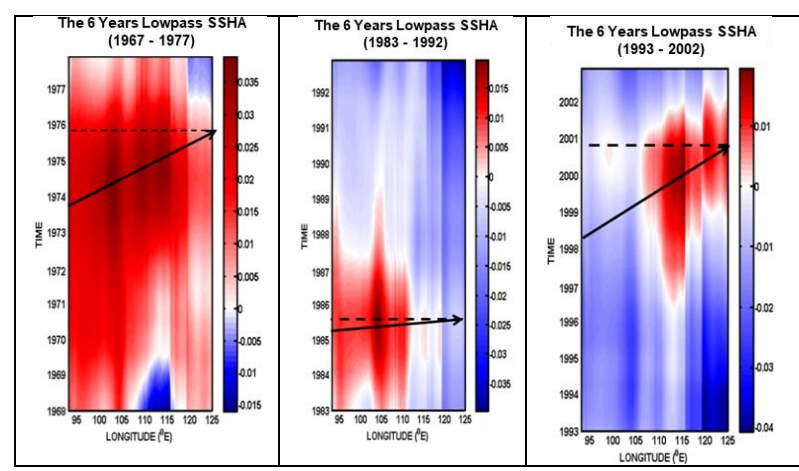

Fig 3. The visual analytic byHovmöller diagram of the low-pass filter data by 8 years cut-off of the SSHA data in the western of Sumatra and Southern of Java during 1950 to 2013. There were three eastward propagations that indicated as a decadal Kelvin wave

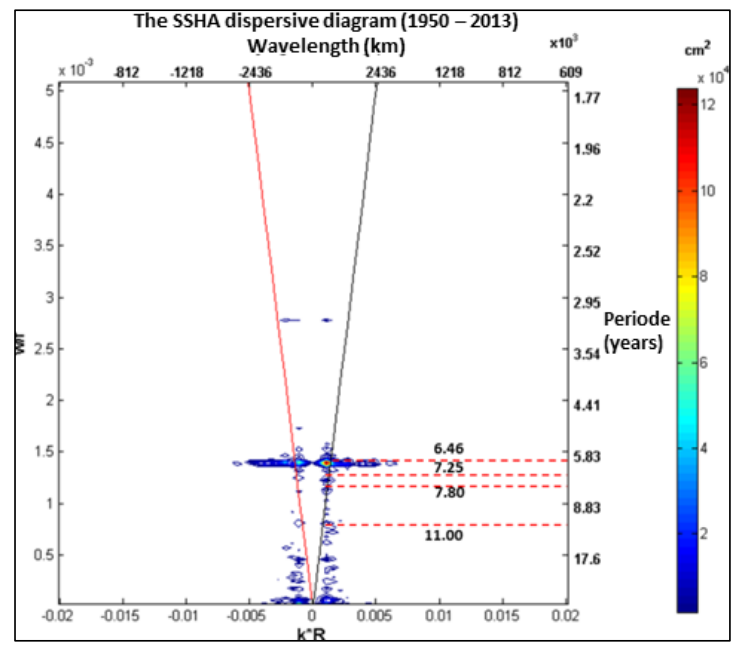

Fig 4. The energy spectrum plotted by using frequency-wavenumber 2D spectral analysis (dispersive diagram) for raw data. These were several the Kelvin wave energy spectrums

We had proven the existence of the decadal Kelvin wave trough the dispersive diagram of the SSHA data. Moreover, trough the energy spectrum of the temperature, the existence of the Kelvin wave can be observed too. Figures 6 to 9 are the plot of the energy spectrum of the temperature at a depth of 10,80 , 150 , and $220 \mathrm{~m}$ by using frequency - wavenumber $2 \mathrm{D}$ analysis. Based on that, there were several energies that coincide to the black lines. It proves that by the energy spectrum of temperature plot could show the existence of the Kelvin wave propagation.

The Kelvin wave was identified with a period of 3.43 and 7.3 years by dispersive diagram. Meanly, it proves that in the western of Sumatra and along the southern of Java have the decadal of Kelvin wave. In Figures 6 to 9 was indicated by thedecadal Kelvin wave propagation with a period of 7.3 years at depths of 10, 80, 150, and $220 \mathrm{~m}$. As well as Figures 6 to 9, the decadal Kelvin wave has also identified with a period of 7,25 years by using dispersive diagram of the SSHA data.

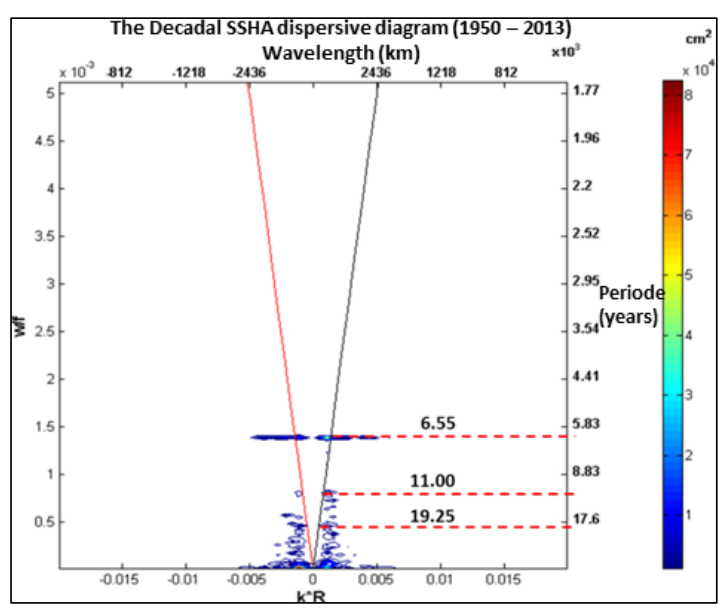

Fig 5. The energy spectrum plotted by using frequency-wavenumber 2D spectral analysis (dispersive diagram) for 8 years low-pass filter data. These were several the Kelvin wave energy spectrums.

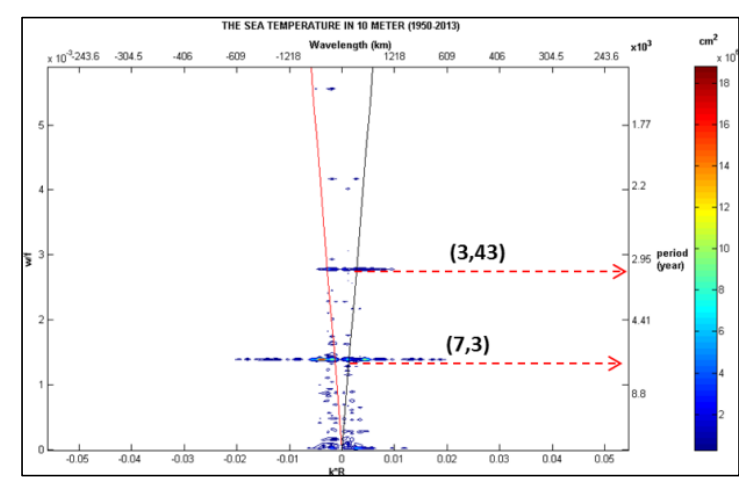

Fig 6. The energy spectrum plotted by using frequency-wavenumber 2D spectral analysis (dispersive diagram) for the depth temperature of $10 \mathrm{~m}$. These were several the Kelvin wave energy spectrums.

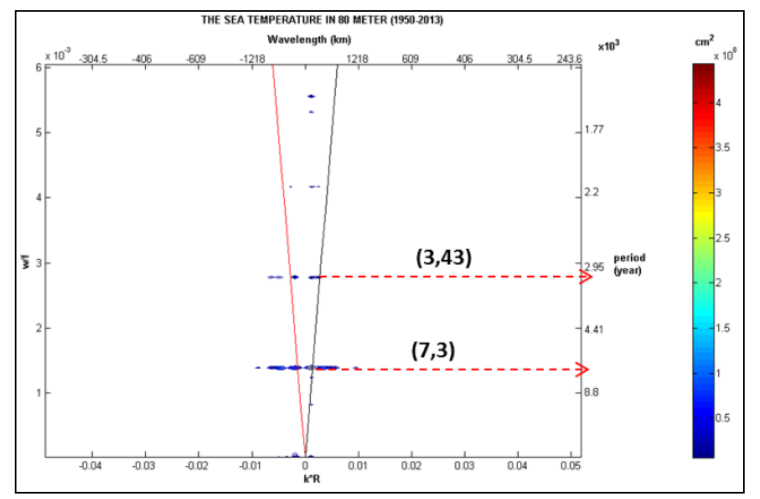

Fig 7. The energy spectrum plotted by using frequency-wavenumber 2D spectral analysis (dispersive diagram) for the depth temperature of $80 \mathrm{~m}$. These were several the Kelvin wave energy spectrums. 


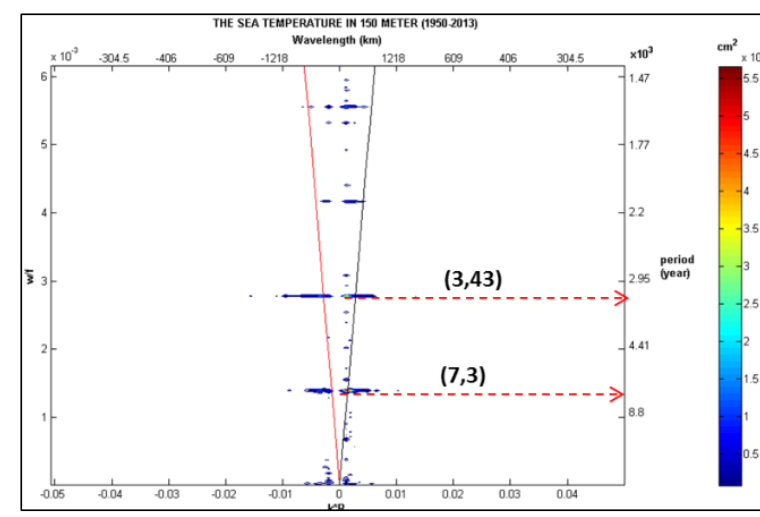

Fig 8 . The energy spectrum plotted by using frequency-wavenumber 2D spectral analysis (dispersive diagram) for the depth temperature of $150 \mathrm{~m}$. These were several the Kelvin wave energy spectrums.

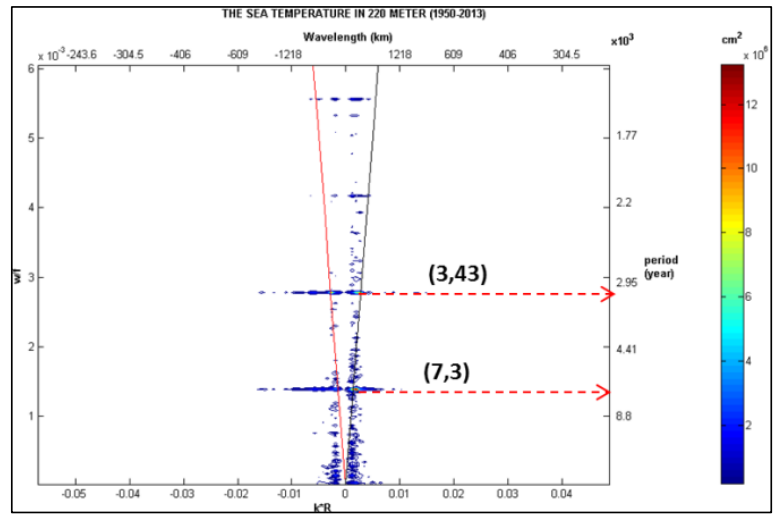

Fig 9 . The energy spectrum plotted by using frequency-wavenumber 2D spectral analysis (dispersive diagram) for the depth temperature of $220 \mathrm{~m}$. These were several the Kelvin wave energy spectrums.

\section{Conclusion}

The decadal Kelvin wave has been identified in the western of Sumatra Island and along the southern of Java with a period of 19.25 (inter-decadal) and 11 years (decadal) by using the Hovmoller diagram and proven by frequency-wavenumber 2D spectral analysis (dispersive diagram). Thesehave phase speed (propagation velocity) as well as $1,029 \times 10^{-3} \mathrm{~m} / \mathrm{s}$ (1974 to 1976) and $0.21 \mathrm{~m} / \mathrm{s}(1985-1986)$. In the other way, the Kelvin wave propagation can be showed by dispersive diagram of depth temperature, and its period was a 7.25 years. The occurrence of the Kelvin wave has a relation to IOD index. The average of the IOD index when the decadal Kelvin wave was occurring must be the negative value, its value was a -0.21 .

\section{References}

Clarke, C. O., P. J. Webster, and J. E. Cole. 2003. Inter-decadal Variability of the Relationship between the Indian Ocean Zonal Mode and East African Coastal Rainfall Anomalies. Journal of Climate, 16:548 - 554

Cooley, J. W and J. W. Tukey. 1965. An algorithm for the machine calculation of complex Fourier series. Mathematics of Computation, 19:297-301.

Grinsted, A., J. C. Moore, and S. Jevrejeva. 2004. Application of the Cross Wavelet Transform and Wavelet Coherence to Geophysical Time Series. Nonlinear Processes in Geophysics, 11: 561 - 566.

Han, W., J. W. Wang, and J. Weiss. 2008. Interannual Variability and Decadal Change of Themocline Depth and Upper Ocean Heat Content in the Indian Ocean. Department of Atmospheric and Oceanic Sciences (ATOC). USA
Iskandar, I., W. Mardiansyah, Y. Masumoto, and T. Yamagata. 2005. Intra-seasonal Kelvin Waves along the Southern Coast of Sumatra and Java. Journal of Geophysical Research, 110: C04013.

Khoirunnisa, H. 2015. The Interannual and decadal variability of the sea surface height anomalyaqlong the Southern of Java. Thesis of Oceanography study program. Bandung Institute of Technology.

Mahongo, S., M. Nguli, and J. Francis. 2014. Inter-annual and Decadal Oscillations of Sea Level in the Western Indian Ocean. Geophysical Research Abstracts, 16: EGU20146153-2.

Mann, M. E., and J. Park,1996. Joint spatiotemporal modes of surface temperature and sea level pressure variability in the northern hemisphere during the last century, J. Clim., (in press)

Mantua, N. J., and S. R. Hare. 2001. The Pacific Decadal Oscillation. Journal of Oceanography, 58: $35-44$.

Ningsih, N. S., S. Hadi, I. Sofian, Kunarso, and F. Hanifah. 2012. Kajian Dampak Perubahan Iklim Terhadap Dinamika Upwelling Sebagai Dasar Untuk Memperkirakan Pola Migrasi Ikan Tuna di Perairan Selatan Jawa - Nusa Tenggara Barat dengan Menggunakan Model Transpor Temperatur Laut. Laporan Riset dan Inovasi KK.Institut Teknologi Bandung. Bandung.

Park, W. S., and I. S. Oh. 2000. Interannual and Interdecadal Variations of Sea Surface Temperature in the East Asian Marginal Seas. Progress in Oceanography, 47: 191 - 204.

Qian, W., H. Hu, Y. Deng, and J. Tian. 2001. Signals of Interannual and Interdecadal Variability of Air-Sea Interaction in the Basin-Wide Indian Ocean.Atmosphere - Ocean, 40: 293 - 311.

Roisin, C.B. and M. B. Jean. 2008. Introduction to Geophysical Fluid Dynamics. Academic Press.

Saji, N. H., B. N. Goswami, P. N. Vinayachandran, and T. Yamagata. 1999. A Dipole Mode in the Tropical Indian Ocean. Nature, 401: 360 - 363.

Schott, F. A., S. P. Xie, and J. P. McCreary Jr. 2009.Indian Ocean Circulation and Climate Variability.Reviews of Geophysics, 47: RG1002.

Sambodho, K., Zikra, M., Yunita, N. F., \& Syahroni, N. (2017). Variability of Sea Surface Chlorophyll and Temperature Using Remote Sensing to Support Marine Aquaculture in Indonesia. International Journal of Civil Engineering and Technology, 8(8).

Sprintall J., A. L. Gordon, R. Murtugudde, and R. D. Susanto. 2000. A Semiannual Indian Ocean forced Kelvin Wave Observed in the Indonesian Seas in May 1997. Journal of Geophysical Research, 105: 17,217 - 17,230.

Stewart, R. H. 2008. Introduction To Physical Oceanography. Department of Oceanography Texas A \& M University.

Susanto, D. R., A. L. Gordon, and Q. Zheng. 2001. Upwelling along the Coasts of Java and Sumatra and its Relation to ENSO. Geophysical Research Letters, 28: 1599 - 1602.

Syamsudin, F., A. Kaneko, and D. B. Haidvogel. 2004. Numerical and observational estimates of Indian Ocean Kelvin Wave intrusion into Lombok Strait. Geophysical Research Letters, 31: L24307.

Syamsudin, F. 2004. Semiannual Kelvin Waves Propagation Along the South Coast of Sumatra - Jawa - Bali and The Lesser Sunda Islands Observed by TOPEX/POSEIDON and ERS - 1/2 Satellites. PROC. ITB Eng. Science, 36 B: $133-139$.

Tomczak, M., and J. S. Godfrey. 2001. Regional Oceanography: An Introduction. Permagon.Tarrytown. New York. 
Wang, Y. H. 2010. The Tutorial: S-Transform. National Taiwan University.ROC.

Wisha, U. J., \& Khoirunnisa, H. Sea Surface Temperature Rising Trend and Its Influence on the Coral Mortality in Pagai Strait, Mentawai Islands, Indonesia. International Journal of Civil Enggineerig and Technology (IJCIET), $8(10), 725-734$.
Yuan, Y., Chan, C. J., Zhou, W., \& Li, C. (2008). Decadal and interannual variability of the Indian Ocean Dipole. Advances in Atmospheric Sciences, 25(5), 856-866.

(CC) (1) (O) 2016 Journal of Geoscience, Engineering,
Environment and Technology. All rights reserved. This
is an open access article distributed under the terms of 